\title{
"BANDA DE LOS SUPREMOS PODERES”, VERTIENTE DE MÚSICOS EXTRANJEROS
}

José Alfredo Ramírez Fuentes Universidad de El Salvador freddy_jarf81@yahoo.com

Recepción: 30 de marzo de 2016 Aceptación: 13 de abril de 2016 


\section{RESUMEN}

El siguiente ensayo tiene por objetivo dibujar en líneas generales el surgimiento y primeros años de la Banda de los Supremos Poderes. Esta Banda de carácter estatal inició como una mera banda marcial y evolucionó, de mano de directores nacionales y extranjeros, hasta convertirse en una entidad de carácter profesional a inicios del siglo XX. Sus miembros y su historia son el antecedente inmediato de la Orquesta Sinfónica de El Salvador, formada ya en el siglo XX. Un segundo componente de este escrito es la inmigración. En este sentido, se examina la vida de músicos extranjeros que llegaron a apoyar el desarrollo de la Banda y de la música en El Salvador.

\section{Palabras clave}

Banda - Supremos Poderes - Músicos - Marcial - Filarmónica - Sinfónica Conciertos

\section{ABSTRACT}

The following essay aims to draw in general the emergence and early years of the Band of the Supreme Powers. This band state character began as a mere marching band and evolved, hand-held domestic and foreign directors, to become an entity of professional nature in the early twentieth century. Its members and its history are the immediate background of the Symphony Orchestra of El Salvador, already formed in the twentieth century. A second component of this paper is immigration. In this sense, the life of foreign musicians who came to support the development of the band and music in El Salvador is examined.

\section{Keywords}

Band - Supreme powers - Musicians

- Martial - Philharmonic - Symphony

- Concerts 


\title{
"BANDA DE LOS SUPREMOS PODERES”, VERTIENTE DE MÚSICOS EXTRANJEROS
}

\author{
José Alfredo Ramírez Fuentes \\ Universidad de El Salvador \\ freddy_jarf81@yahoo.com
}

\section{Introducción}

Los diferentes pueblos del mundo a lo largo de la historia han estado en constante intercambio -ya sea por el comercio, por relaciones diplomáticas, intercambios culturales o por la simple motivación del hombre por explorar el mundo- podemos afirmar que la migración, es un movimiento en doble vía, que constantemente lleva a distintas personas o grupos sociales, a emprender viajes de un lugar a otro. Ya en una época moderna se concibe la migración en dos vertientes: por un lado, la emigración que se entiende bajo la lógica de ir de un país o lugar de origen a otro, concibiendo este movimiento como de desplazamiento hacia fuera; la otra vertiente sería la comprendida como inmigración, donde un lugar de llegada recibe a individuos, o incluso, cierta cantidad de personas que se quedan en este lugar por cierto tiempo, este movimiento se entiende como un desplazamiento hacia dentro. Estos movimientos no dependen de un tiempo de duración, que determine el movimiento migratorio. 
Entendidos los conceptos de la migración nos podemos enfocar en uno de ellos: la inmigración, y dar paso al segundo elemento que nos interesas tratar: el arte. El arte como expresión humana, surge y se desarrolla a la par con la humanidad, evolucionando con las sociedades a medida ellas hacen lo propio en todos los complejos aspectos que la integran. Más concretamente nos interesa tratar dentro del arte, la música y de esta las primeras instituciones que surgen en El Salvador.

Ambos aspectos, la inmigración y las instituciones musicales son los hilos conductores que nos llevaran a lo largo del presente ensayo. Sin duda, surge la pregunta ¿qué tienen que ver las instituciones musicales con la inmigración? Entremos un poco más en detalle.

El desarrollo de la música en los primeros años de El Salvador como estado, primero y como república, después, es muy precario, lo cual es comprensible si tomamos en cuenta que la sociedad colonial no tenía dentro de sus prioridades el desarrollo del arte. Una vez que se logra la independencia, y más aún con el fracaso de la República Federal Centro Americana, los países de la zona sienten la necesidad de incorporarse al mundo, política y económicamente quieren alcanzar la modernidad, identificarse como nación.

En este marco de necesidades se inicia la política de crear instituciones que representen a El Salvador en el mundo: por ejemplo, Instituciones de Gobierno, la Universidad Nacional, los primeros colegios de educación básica, un Obispado; y muchos otros elementos que le dan fuerza al nacionalismo que se trata de impulsar.

Es muy interesante resaltar que un gran impulso a la música, en sus primeros años como arte, se lo diera la iglesia católica; es esta institución, por medio del primer obispo de El Salvador, la que trae a Escolástico Andrino, como director de coros y profesor de música, el cual establece una escuela privada en San Salvador. Pero también otra institución fomenta el que se tome la decisión de contratar músicos extranjeros para formarse en este arte, las bandas militares, siendo las primeras la "Banda del primer regimiento 
de Infantería" y la "Banda de los Supremos Poderes". Son los directores de ésta los que llegan a El Salvador para canalizar sus enseñanzas a los músicos nacionales, y colaborar con la cultura del país, mismos que son el objeto de nuestro estudio ya que reúnen las características de ser inmigrantes y músicos.

Estos personajes están relacionados solo por la banda, que nos servirá como "pegamento", ya que por medio de dicha institución podemos establecer cuando llegan al país estos músicos, cuáles son los cargos que utilizan, en fin cuál es su aporte y a partir de ahí, investigar cómo se integran o adaptan a la sociedad salvadoreña, ellos e incluso su familia y descendencia. Volvamos aquí un poco a las definiciones teóricas ${ }^{2}$ que nos ayudarán a entender mejor el fenómeno, auxiliándonos de la antropología que integra el fenómeno migratorio en tres dimensiones, -histórica, sociológica y psicológica- llegamos a interrogarnos ¿por qué estos músicos extranjeros llegan a El Salvador?, y más importante aún, ¿porqué se quedan?

Para responder a estas preguntas tenemos que señalar que el comportamiento humano responde a motivaciones, y dentro de la inmigración se pueden dividir en dos variables: por un lado, las motivaciones objetivas y por otro, las motivaciones subjetivas. A estas últimas creemos que responderían la mayoría de músicos que llegan a territorio salvadoreño. Probablemente estos artistas ven la oportunidad de un mayor desarrollo profesional y de lograr un reconocimiento, muy dificil de alcanzar en sus países de origen, o bien responden a contratos a larga distancia a iniciativa del gobierno salvadoreño; tal vez no fueron por estas razones, sino que fueron impulsados a salir de sus patrias por razones personales. Sería muy difícil establecer las razones por las que la gran variedad de extranjeros salen de sus países y de-

\footnotetext{
${ }^{1}$ Inicialmente a esta institución se le conoce como banda militar, simplemente; luego se le da el nombre de "Banda Marcial" y finalmente se le conoce como "Banda de los Supremos Poderes".

${ }^{2}$ Sélim Abou. Los aportes culturales de los inmigrados. Metodología y conceptualización. En: Leander, Brigitta (coord.) Europa Asia y África en América Latina y el Caribe: Migraciones "libres" en los siglos XIX y XX y sus efectos culturales. (México: siglo XX editoriales UNESCO, 1989), 369.
} 
ciden quedarse en lugares como El Salvador, pero examinando los distintos cargos podemos aproximarnos a las motivaciones de cada persona y más importante aún, tratar de esbozar sus aportes a la cultura receptora.

También podemos afirmar que algunos músicos recorren Centro América, haciendo su obra en varios países y que otros se instalan en El Salvador durante toda su vida. Para estos últimos es aún más importante ver cómo contribuyen al país y como, a veces, incluso su grupo familiar se integra, por lo general a la clase media salvadoreña. Aquí se utiliza el término integración, aunque se pueden adoptar distintos conceptos dependiendo del caso a ser analizado. Entre los que servirán en este trabajo nos encontramos, una vez más recurriendo a la antropología, ${ }^{3}$ con los siguientes: en primer lugar, encontramos la adaptación, que se utiliza para designar el acomodamiento - es decir contar con los elementos básicos para vivir- de los inmigrantes al medio físico del país receptor y a su nuevo ambiente. Un segundo sería el concepto de integración, donde los inmigrantes, e incluso su descendencia, se insertan en las estructuras sociales, económicas y políticas de la sociedad que los recibe. Por último, encontramos la aculturación, que sirve para designar los fenómenos de interferencias que son el resultado de la confrontación del sistema cultural original y de los inmigrantes con la sociedad receptora, así como los cambios subsiguientes en los modelos de uno y/u otro sistema. Será necesario toma cada ejemplo como único y analizar en qué medida se han adaptado, integrado o aculturizado los músicos inmigrantes a la sociedad salvadoreña.

Conviene también llamar la atención sobre otros aspectos, para determinar los aportes culturales de los músicos inmigrantes, estos aportes se pueden dimensionar en tres niveles. La difusión de rasgos culturales en la sociedad salvadoreña; el cambio operado por la aculturación tanto de los inmigrantes como de la sociedad receptora; y finalmente la formación de una nueva entidad cultural característica de los inmigrados.

\footnotetext{
${ }^{3}$ Abou, 1989
} 
En especial, para este trabajo conviene destacar que los músicos llegados al país vienen a impartir enseñanzas, es decir parte de su cultura, en cuanto a este punto el autor Selim Abou nos dice: "Con razón cada grupo étnico [persona] hace valer con orgullo las obras literarias y artísticas que han suministrado a la sociedad receptora, las ideas sociales o políticas que ha contribuido a difundir y las técnicas de diverso tipo que han introducido en esta sociedad"4.

Pero es indispensable comprender estos elementos en las dimensiones: histórica, es decir, a partir de que fenómeno se han difundido en la sociedad y sus etapas; sociológica, en que grupos o clases de la sociedad se ha difundido; y psicológica, en qué medida la población las ha modificado según sus necesidades y sus características propias.

Una vez comentados los conceptos que nos ayudarán a comprender el proceso de inmigración, parece lógico hacer lo mismo con los conceptos relacionados con la música, empezando por explicar cómo entendemos en el presente trabajo la música, que no es en su concepción académica, sino más bien relacionada con la historia. Así la música se entendería como una práctica social, inmersa en un contexto económico, político, social y cultural. Además se propone entender los diferentes procesos que afectaron su producción, ejecución, distribución y recepción durante el período a ser estudiado. ${ }^{5}$ De acuerdo con la nueva corriente historiográfica, se trata de explicar la historia no solo desde el punto de vista de la estructura material, sino que integra la cultura como factor explicativo. Dentro de esta corriente se estudia lo institucional y formal, como lo cotidiano y popular. Desde el punto de vista musical se estudia a los compositores, las obras musicales y las instituciones, así como la música en funciones política y social. De estos últimos, ambos aspectos estarán incluidos, las bandas suelen acompañar las

\footnotetext{
${ }^{4}$ Abou, 1989

${ }^{5}$ Clara Vargas Cullell De las Fanfarrias a las Salas de Concierto, Música en Costa Rica (18401940). (Costa Rica, Editorial de la Universidad de Costa Rica, Asociación Pro-historia Centro Americana, 2004), 292.
} 
campañas militares; pero en El Salvador al carecer de instituciones de formación musical, la banda a fines del siglo XIX abandona su función puramente militar y la combina con funciones de tipo social, como se verá en el desarrollo del trabajo. También es importante analizar cómo se formó esta banda, quiénes contrataron a los directores y bajo qué condiciones llegan al país, como les pagaron y con qué propósitos se utilizó la música. De esta forma la música se convierte en un factor completamente integrado a la sociedad, y en un elemento de formación de un estado nacional.

Finalmente, el uso que el estado dio a este cuerpo de banda, como por ejemplo: la forma política de la música, en himnos y canciones para personalidades del ambiente político; roles ceremoniales, en ceremonias pública; actividades no oficiales, escénico musicales y en veladas, fiestas, retretas, donde estas actividades configuran un lugar público de socialización. Es importante darnos cuenta que las instituciones formales e informales son de vital importancia en la diferenciación social dentro de la sociedad, para la élite, demuestran la adquisición y prestigio de la sociedad europea tan admirada.

\section{Nacimiento de la banda}

El Salvador a mediados del siglo XIX, aun era lo que algunos denominan protonaciones, es decir que era un estado de la fracasada República Federal y al igual que los demás países de la región, sus élites luchaban por definirse como una nación. Tratando de imaginar la región, allá por 1841, El Salvador se mantenía en la tranquilidad de la vida cotidiana, que no era muy diferente a su realidad colonial recién superada. La más grande diferencia, tal vez radicaba en que San Salvador ya no era un gobierno local subordinado a una gran metrópoli al otro lado del Océano Atlántico, en su lugar había pasado a ser la capital de un nuevo país. La nueva república, inmersa en impulsos por crear en la población ese sentimiento de pertenencia, creó muchas instituciones gubernamentales principalmente. Pero también se apropió de otras heredadas de tiempos pasados, dándole a estas una visión de carácter 
nacional, entre ellas las militares -las milicias- eran un referente muy activo que desde el período federal siempre respondieron a los intereses locales de los estados.

Unido a la anterior reflexión, se dieron desde diferentes vertientes culturales y artísticas iniciativas para desarrollar la música, ¿precariamente? Sí, es cierto, pero ubiquémonos en el tiempo y reflexionemos ¿qué más se podía esperar?, era el inicio de algo que debía desarrollarse en el transcurso de los años. Proponemos aproximarnos a esta evolución, propiciada por personajes extranjeros que llegan al país para contribuir con la "Banda de los Supremos Poderes", desde su fundación, hasta su transformación en los primeros años del siglo XX, cuando se convierte en la "Orquesta Sinfónica de los Supremos Poderes".

Regresamos en el tiempo hasta 1841, cuando se funda la banda, esta acción se dio con el propósito de organizar una banda militar, entendiendo ésta como un conjunto de instrumentos que forman parte de las campañas militares, principalmente conformadas por instrumentos de percusión y viento-metal, teniendo a su vez la tradición y ejemplo de las bandas militares, que acompañaban a la unidades de caballería e infantería europeas. Esta primera banda salvadoreña se fundó con la intención de organizar los grupos de músicos que acompañaban a las milicias, con el propósito de formar una banda respetable; es decir, no unos cuantos tamborileros y cornetas rudimentarios, que arriesgan su vida en las campañas militares, sino que se quería formalizar un ejército y por tanto también organizar correctamente el conjunto de músicos que acompaña a estos.

Esta banda tiene sus orígenes en la ciudad de San Miguel, donde casualmente ${ }^{6}$ llegan los filarmónicos Juan Guido, de origen Italiano; Manuel

\footnotetext{
${ }^{6}$ Rafael González Sol. Historia del arte de la música en El Salvador. (San Salvador, Imprenta Mercurio, 1940), 10
} 
Navarro, de nacionalidad española; y José María Martínez de la Rosa ${ }^{7}$, también español quienes llegaron a El Salvador en 1841 donde fueron contratados por el gobierno por cien pesos cada uno, para formar y dirigir la Banda Militar nacional, procurando también enseñar a estos "músicos" a ejecutar correctamente los instrumentos que cada uno interpretaba.

Al preguntarnos del por qué de la inmigración de estos personajes, es ciertamente muy difícil de interpretar, lo que sí se encuentra en las fuentes es que los tres llegan a El Salvador procedentes de $\mathrm{Cuba}^{8}$, y se quedan en este país a raíz de su contrato como músicos. José Martínez funge como director de la Banda durante el año de 1841 y algunos meses de 1842. Luego pasó a Guatemala a dirigir la banda de ese país. Rafael Vásquez, relata este acontecimiento así: "Más tarde el general Carrera, encontrándose en la ciudad de Ahuachapán, fue obsequiado por las autoridades salvadoreñas con una serenata que ejecutó la Banda militar de San Salvador, que dirigía el señor José Martínez".9

Luego de este encuentro, Martínez emigró a Guatemala, y formó junto con Juan Matheu, una banda similar a la de San Salvador en aquel país a iniciativa del Gral. Carrera. Ocupó este puesto durante tres años, y luego salió de Guatemala por razones políticas.

Este mismo personaje aparece en Costa Rica, en el año de 1845, donde el estado lo contrató por 200 pesos para que fuera el director de la primera Banda de ese país: "La contratación de José Martínez como profesor de las músicas militares, fue el primer intento, por parte del estado, para mejorar la práctica musical del país"10.

\footnotetext{
${ }^{7}$ Esta conclusión se obtiene luego de consultar varías fuentes, entre ellas el libro "De las fanfarrias a las salas de concierto", "Historia de la música en Guatemala", y en el articulo "Personal de la banda de los Altos Poderes de El Salvador" donde se ha logrado comprobar la presencia de este personaje al menos en tres países Centroamericanos. Cada una de las fuentes cita de distinta forma los nombres a este personaje y así se logró reconstruir el nombre completo de este primer director.

${ }^{8}$ González Sol, 1940

9 Rafael Vásquez A. Historia de la Música en Guatemala. (Guatemala: Tipografia Nacional, 1950), 142

${ }^{10}$ Vargas Cullell, 2004
} 
Podemos interpretar que la adaptación temporal de este músico a El Salvador, se debió al contrato emitido por el gobierno, a iniciativa del Coronel Manuel Cañas - padre del Gral. Juan J. Cañas- y que se dio para suplir una necesidad del ejército y la sociedad del momento. Esta vanguardia de El Salvador en la música militar, como se puede observar, es fruto de la preocupación y de la capacidad del gobierno para poder contratar músicos. No hay que amplificar este suceso, pero hay que darle su mérito. Es muy dificil establecer el aporte real de este individuo, queda por investigar las piezas musicales que se enseñaron, los instrumentos sobre los que los músicos se aplicaron y otros aspectos que no quedan claros.

En los años que siguen la Banda tuvo varios directores entre los que se encuentran: como segundo director después de Martínez; Francisco Libons, Guatemalteco, quien se encuentra a cargo en 1843, y de quien también se sabe estuvo en Costa Rica, donde en 1847 dirigió la banda que organizó José Martínez, fungiendo como su tercer director. Muy poco se sabe de la obra de este director en El Salvador, solo un comentario en boca del primer obispo de San Salvador, Dr. Jorge Viteri y Ungo, a su regreso de Roma: “... entre tanto la música marcial cuyos adelantos, desde que el hábil profesor Francisco Libons la doctrina, son verdaderamente admirables, halagaba el oído de los inteligentes y aumentaba la alegría de la multitud"11.

Después de él solo fue posible encontrar algunos nombres de los directores de la banda, entre ellos: Joaquín Navarrete y Juan Guido.

Continuando con esta red profesional que se empieza a tejer, podemos observar que los directores que siguieron al mando de la Banda Militar, no siempre fueron extranjeros, pues para la segunda mitad de la década de 1850, ya encontramos músicos nacionales formados que pudieron tomar el puesto, entre ellos Don Rafael Orozco que en 1859 dirigía la recién nombrada Banda Marcial, que es la misma objeto del presente estudio con distinto nombre.

\footnotetext{
${ }^{11}$ S.A. Kaleidoscopio salvadoreño. Personal de la banda de los Altos Poderes de El Salvador. En: La Quincena, Tomo I, Num. 11, (1 de septiembre de 1903), 388
} 
Sin embargo, es claro que en esos años donde las comunicaciones eran rudimentarias, las innovaciones las traían agentes externos a la sociedad salvadoreña y en el caso de la música dos hechos son claros, los adelantos más grandes venían de Europa, vía Cuba, pues era esta colonia, todavía en manos de España, la que se beneficiaba de los avances en el arte de Europa más directamente. Segundo, de esta isla llegaban a Centroamérica los músicos, donde algunos de ellos recorrían el istmo quedándose donde podían trabajar.

\section{Su desarrollo y evolución, de la mano de extranjeros}

El desarrollo de la Banda se ve beneficiado con la incorporación de varias personalidades dignas de recordar, es interesante ver cómo cada uno de ellos fue impartiendo su conocimiento a sus alumnos, cómo se plantaron frente a una banda y la dirigieron, no solo para alcanzar reconocimiento, sino para entretener a las personas que escuchan. Las funciones de las bandas son muchas y es evidente que el Gobierno salvadoreño deseaba cultivar la "civilización", la "buena" cultura, discursos muy persuasivos de la época que denotan una gran admiración por los países desarrollados, quienes hacían el papel de modelos a seguir.

Es muy importante dejar claro los cambios de este tipo de bandas filarmónicas, de bandas puramente militares que, como se dijo más arriba, eran parte de los cuerpos militares, pasaron a ser conjuntos musicales que se integraron a la sociedad civil salvadoreña. En un primer momento ellos tomaron un papel muy importante psicológicamente, dentro de las campañas militares. Eran ellos quienes, en épocas musicales muy primitivas eran utilizados para diversas actividades, por ejemplo, en un momento donde se necesitaba llamar la atención de las personas para ceremonias cívicas, escuchar las palabras de algún personaje del gobierno, o alguna declaración de última hora, ellos eran los indicados para tocar sus instrumentos. Algún tiempo después, a medida fueron llegando las innovaciones, mejores y mayor número de obras musicales, mejorías en los maestros y por tanto en los músicos 
alumnos, y aumentaron el número de estos, fue creciendo el interés por este tipo de arte y con ello la banda se transformó para llegar a integrar una serie de conciertos, retretas y fiestas privadas que se vieron halagadas y encantadas con el espléndido sonido de los instrumentos, la admiración y orgullo de la sociedad de fines del siglo XIX, se vio aumentada hacia esta Banda.

Teniendo en la dirección, al señor Alfredo Lowental este cuerpo de filarmónicos, continuó su desarrollo en la escena nacional en el año de 1860, ocupando el puesto dejado por el director de tiempos pasados Rafael Orozco. No está claro ni la nacionalidad, ni cómo llega a El Salvador este músico, lo que sí es admirable es su contribución a la cultura. Impulsado por el ambiente musical y cultural que empieza a vislumbrarse en la sociedad salvadoreña del momento, fue el segundo director de la Academia de Bellas Artes en 1869, y fundador de la primera revista musical en el año de 1870, hasta aquí con los aportes culturales de este personaje; no fue posible reconstruir en gran medida las vicisitudes de él en este país pero su aporte a la Banda, tema que nos importa y mueve, fue mínimo pues apenas duró unos meses en el cargo.

Fue sustituido por el director de Banda y maestro de música instrumental, el señor Alexis Cousin, de nacionalidad Belga y que llega al país por contrato con el gobierno en 1860. Como dato curioso apenas un año antes de que llegue Cousin al país, El Salvador y Bélgica firman un "Tratado de amistad, Comercio y navegación", ${ }^{12}$ esto sucede el 15 de febrero de 1859 , poco tiempo después son obvios los intercambios incluso culturales entre los dos países.

Este personaje es recordado en la historia nacional debido a que es él quien organiza propiamente la banda, y bajo su dirección se le nombra "Banda de los Supremos Poderes". Entre sus contribuciones encontramos la difusión de algunas obras musicales como la marcha militar "Suavos de la

\footnotetext{
${ }^{12}$ Augusto Ulloa Cruz, y T’kint,. Tratado de Amistad, de Comercio y de Navegación entre la Republica del Salvador y la Bélgica, celebrado en Cojutepeque el 15 de febrero de 1859.(Diario Oficial, Tomo 9, Num. 7, 11 de agosto de 1860), 1-4.
} 
Reina”, el vals "Guardias de la Reina” y finalmente, el paso doble o marcha "Reina Victoria" que es conocida hasta nuestros días como la marcha "Gerardo Barrios", debido a que la gente le llamaba de esa forma, al recordar el entusiasmo despertado en el General Barrios cada vez que escuchaba la citada melodía. Es muy importante su aporte, le da una formación "moderna" a la Banda y es miembro activo de la sociedad, se desempeña como director de la Sociedad Filarmónica Salvadoreña, fundada en 1875 y cuyo presidente era Manuel Ayala. Con esto se puede ver que no fue un simple director de banda, fue también entusiasta impulsor del arte musical en el país, al cual se adapta por un periodo de 10 años aproximadamente, tiempo que también marca su estancia al frente de la Banda.

El doctor Rafael Zaldívar de viaje en Alemania, probablemente en funciones diplomáticas, contrató por parte del gobierno a Emilio Dresner, un director de banda en ese país, muy competente y con posibilidades de desarrollarse como tal, procurando los adelantos necesarios en el ambiente musical salvadoreño. Llegó al país a finales de julio de 1870, en el primer concierto al mando de esta organización musical estrenó dos composiciones de su autoría, una titulada "mi salutación a El Salvador", la otra "Independencia"; además es autor de "Melodías del Norte".

Este viajero no venía solo, lo acompañaba su esposa quien era pianista y cantante, y contribuyó al ambiente salvadoreño educando a señoritas de las capas medias y altas de la sociedad con las habilidades artísticas que poseía. Probablemente teniendo problemas en Alemania o con la ilusión de ganar fama en El Salvador, sale este director, de aquel país europeo sin ánimos de regresar. Si bien Dresner pensaba en integrarse a la sociedad, no lo logra y durante su estancia en territorio salvadoreño, continuó con la obra iniciada por Cousin, y le da a la Banda, la organización que dura hasta principios de siglo XX. Seis años dura su estancia en el país, de aquí pasa a Guatemala donde ocupa los cargos de director de banda, y de su labor se dice: "La música propiamente de armonía no vino a Guatemala hasta que Dressner se hizo cargo de la Banda Marcial; y los rudimentos de armonía no 
fueron impartidos, metódicamente hasta que Dressner tuvo una veintena de discípulos" $" 13$.

Es indudable que en Guatemala se le aprecia mucho como director de banda; pero solo en este cargo, ya que también se encarga de la dirección del Conservatorio, su labor ahí deja mucho que desear y se ve como un error su contratación. Su labor en la zona, y sobre todo en las bandas es muy apreciable, compositor y director, deja a su paso una influencia muy valiosa. En Guatemala se radica permanentemente, no vuelve a El Salvador, pero en este último deja dos obras musicales, las arriba mencionadas, y seis años de su vida y la de su esposa que sirven para acrecentar el caudal de enseñanza musical en el país.

\section{ILUSTRACION 1}

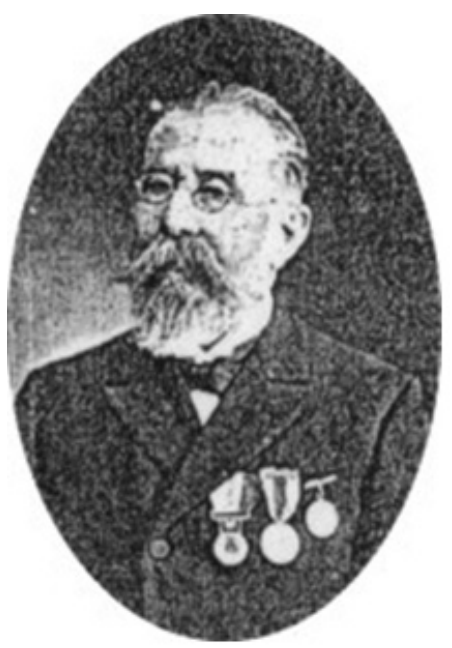

\section{Heinrich Drews}

Fuente: Ward, L.A. Libro Azul de El Salvador. Bureau de publicaciones de América Latina, Imprenta Nacional, 1916, p. 210

\footnotetext{
${ }^{13}$ Rafael Vásquez A. Historia de la Música en Guatemala. (Guatemala: Tipografia Nacional, 1950), 147
} 
En 1876, teniendo el vacío dejado por Dresner, el gobierno contrata a Heinrich Drews ${ }^{14}$, este Alemán se integra a la sociedad salvadoreña de fines del XIX, radicándose en el país hasta su muerte. En los inicios de su labor artística y cultural, el mismo año en que llega al país, toma la batuta de la Banda de los Supremos Poderes, e introduce un repertorio con las obras clásicas más importantes y que nunca habían sido escuchadas en nuestro país, entre ellas: creaciones de compositores de la talla de Wagner, Liszt y Beethoven. En este período también a iniciativa de Drews, el gobierno trae a sobresalientes músicos de otros países centroamericanos, para procurar un adelanto mayor a la música nacional.

Con un número cada vez mayor de músicos, la Banda se llegó a expandir y a ilustrar tanto que llegó a considerarse la mejor Banda u Orquesta de Centroamérica, con más de cien músicos en sus filas. Todo este grupo de filarmónicos participaban en varios eventos a lo largo y ancho del istmo, así demostraron virtuosismo sus solistas y una impecable ejecución en conjunto, en la exposición guatemalteca celebrada durante la administración del Gral. José María Reina Barrios.

Las distintas personas en el país debieron encontrarse muy orgullosos de la Banda, y durante el tiempo que fue dirigida por Drews, se integró por completo a la sociedad civil, presentándose semanalmente en la plaza de la ciudad, interpretando conciertos para el público en general, los viajeros que deambulaban por la zona se admiraban de la gran calidad de la Banda: "La banda militar toca dos o tres noches por semana en la plaza central. Es en estas agradables ocasiones que se amontonaban los ciudadanos. Incluso las barbaridades entonadas de algunos de los grandes compositores eran menos intolerables cuando eran interpretadas por los instrumentos de estos talen-

\footnotetext{
${ }^{14}$ Este director fue conocido en el ámbito nacional con el nombre de Enrique Drews, en este trabajo se utiliza Heinrich Drews, él es alemán y no puede llamarse Enrique que es un nombre castellanizado según la pagina Web: Carlos Cañas Dinarte. Plaza Barrios: Un Predio Histórico. En: http://www.elsalvador.com/noticias /EDICIONES ANTERIORES/julio23/ NACIONAL/nacio8.html visitado el 04-10- 2004. Heinrich, es su verdadero nombre.
} 
tosos músicos. Si un órgano era tocado por las noche, con qué asombroso poder y belleza resonaba por las silenciosas calles"15.

Este músico y compositor se integra a la sociedad salvadoreña, y es respetado como una gran eminencia en el ámbito musical. Formó su familia en territorio salvadoreño y se insertó con su grupo familiar a la sociedad, jubilado después de treinta años de servicios y llevando a la Banda de los Supremos Poderes a sus años dorados, es recordado como gran Maestro quien hizo la diferencia musical a fines del siglo XIX. Incluso podemos observar el grado de integración de su familia ya que uno de sus hijos, Federico Drews a principios de siglo XX, era el gerente del Banco Agrícola Comercial, con lo cual queda claro que él y su descendencia se quedó entre nosotros.

Como ejemplo de la trascendencia de la obra de Drews podemos atribuirle la formación profesional que acompañaría a la Banda hasta sus últimos días; la transformación de lo puramente militar a lo artístico, más civil, dentro de la sociedad es evidente; incluso en los periódicos nacionales se publicaban los eventos donde participaba el conjunto musical de mano del maestro Drews:

\section{"El Parque esta Noche}

La banda que dirige H. Drews dará esta noche el concierto en el Parque Bolivar con el siguiente programa:

1. Roscana, paso doble (Micons)

2. Obertura de la ópera Rienzi (Wagner)

3. España-Vals (Waldteufel)

4. Belladora (Nehl)

5. Fantasía de la ópera (Meyerbeer)

6. Vielliebchen. Cuadrillas (Meisel)"16

\footnotetext{
${ }^{15}$ Aldo Lauria Santiago Trabajaban para vivir: Descripción de El Salvador por John Newbigging en la década de 1880 En: Revista Mesoamérica, No. 42( Junio de 2002), 124

${ }^{16}$ S.A. "El parque esta noche". En: Diario del Salvador, lunes 5 de agosto de 1895 p. 3.
} 
El parque Bolívar era el escenario para varios y variados conciertos, anuncios como el anterior son comunes en los periódicos, pero también se dedicaba a dar conciertos en fiestas privadas, y encuentros de gala o diplomáticos, y fiestas cívicas, donde la banda era esencial.

Sin dudas el director Heinrich Drews fue lo mejor que le pudo pasar a la Banda, pues bajo su mando alcanzó su pleno desarrollo. Después ocuparía su lugar un compatriota suyo, siendo de esta forma tres directores alemanes seguidos quienes tomaron la batuta y dirigieron la banda, su nombre era Karl Malhmann, durante poco tiempo ocupó el cargo de director, ya que entrado el siglo XX, en el año de 1914, tuvo que regresar a su patria para luchar en la primera guerra mundial. Muy poco se sabe de la vida de este músico, y tampoco se sabe cuánto tiempo se quedó en el cargo, posiblemente solo prestó sus servicios bajo contrato gubernamental.

\section{ILUSTRACIÓN 2}

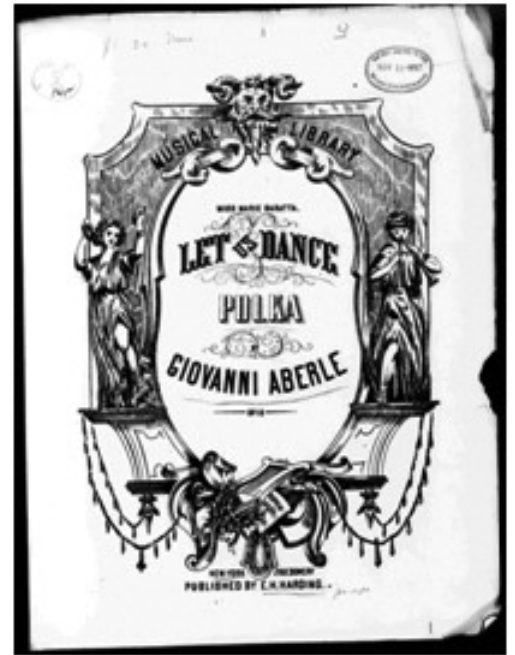

Partitura de Aberle publicada en New York Fuente: Aberle, Giovanni. Let us dance En: http://memory. loc.gov/cgi-bin/am page?collid $=$ mussm\&file Name $=$ sm $/$ sm1871/00500/00545/mussm00545/m visitada el 04-10-2004 
Un personaje que ganó mucha admiración y respeto en la sociedad salvadoreña, es el italiano Giovanni Enrico Aberle Sforza, ${ }^{17}$ conocido como Juan Aberle, en Centroamérica. Este Napolitano, ve la primera luz un 11 de diciembre de $1846,{ }^{18}$ y empieza su vida musical en su país de origen, acudiendo al conservatorio de la citada ciudad italiana. Once años tenía cuando se inició en este arte que sería su pasión de por vida, pronto sobresalió como alumno de los maestros Cesi en cuanto al piano, de Fernando Ponsi en el violín y en composición de Mercadante. Obteniendo su título de maestro, compositor y concertador en 1866.

En 1871 viaja al otro lado del Atlántico, donde se establece en la ciudad de New York, llega impulsado por la música, como director de dos óperas.

En Estados Unidos deja huella, y es una partitura de la polka "Déjennos Bailar” la que nos da la certeza de su estadía en aquel país. De ahí partirá de gira hacia América Latina, llegando a Guatemala donde dirige la escuela de Filarmónicos, y funda el primer conservatorio de esa ciudad.

Siguiendo con su gira, llega a El Salvador el 5 de Junio de 1876, al mando de la misma compañía de ópera que lo ha llevado en su gira, ésta estaba compuesta por músicos extranjeros reconocidos en su época.

Cuando termina la temporada de la ópera en el país, el maestro Aberle es contratado por el entonces presidente Dr. Rafael Zaldívar por 60 pesos, para que dirija la Banda Militar de La Libertad.

Este músico deja su huella en nuestra historia con un hecho muy notable, es él quien compone la música de nuestro actual himno nacional; en 1879 cuando se entonaron sus notas por primera vez en la explanada del antiguo Palacio Nacional, solo era una más de las obras musicales inspiradas y en honor de la república salvadoreña. Hubo que esperar hasta 1953, para

\footnotetext{
${ }^{17}$ Carlos Cañas Dinarte. Los italianos en El Salvador. En: Anuario de investigaciones 3. (CICH, Universidad Dr. José Matías Delgado),164

${ }^{18}$ Miguel Ángel García. Diccionario Histórico, ABA-ANTI. (San Salvador, Tipografia "La Luz", 1927) 567 (Tomo I)
} 
que por un decreto legislativo de diciembre de ese año se declarara himno nacional de El Salvador.

Regresando a la vida de don Giovanni Enrico, nos podemos imaginar las constantes fiestas, y actividades en las que participaba, como director y parte integral de la sociedad salvadoreña. En honor al Dr. Zaldívar, una noche de conciertos ofrecida por tres bandas, componiendo una sola: "En la bellísima pieza compuesta en homenaje al Dr. Zaldívar, mostróse a gran altura nuestro inspirado compositor y los músicos la desempeñaron con perfección arrancando al público merecidos aplausos... Respecto al señor Aberle, teniendo en cuenta sus servicios y el laudable empeño con que este inteligente artista trabajaba en su cargo de Director de la banda militar de Santa Tecla, tuvo a bien el Ejecutivo darle el ascenso de Coronel"19.

Después pasó a ser director de la Banda de Santa Ana, pero renunció en septiembre de 1888, para poder regresar a Guatemala, país al cual llegó en mayo de 1890. Tomó el cargo de director de la Banda Marcial de esa república y además fue director del nuevo conservatorio, bajo su dirección esta institución alcanzó su período de mayor auge, ${ }^{20}$ pero también a causa de ciertos problemas personales fue Aberle el que lo llevó a su decadencia. Así termina su carrera en aquel país vecino y regresa a El Salvador. De nuevo en territorio salvadoreño toma posesión como director de la Banda de los Supremos Poderes en reemplazo de Karl Malhmann, 1914 es el año que inicia su período en este cargo para terminar debido a su avanzada edad en 1922, con el nombramiento de "Director Honorario de la Banda". La difusión de su obra es basta, así como su influencia en la cultura salvadoreña, grandes veladas de arte organizó este personaje, donde nombres como:Adriana Arbizú, Angela Andrade, Mélida Urrutia, Antonia Cañas y Tula Guirola se mencionan como grandes pianistas nacionales; y los señores Tomás Aguilar, Jorge Aguilar y Carlos Peña, cantantes, los poetas Rubén Darío, Mayorga Rivas,

\footnotetext{
${ }^{19}$ García, Miguel Ángel. Diccionario Histórico, ABA-ANTI. (San Salvador, Topografia “La Luz”, 1927),

${ }^{20}$ Vásquez A., Rafael. 1950
} 
Plácido Peña,Vicente Acosta, Manuel Barriere, Juan Delgado y el gran violinista salvadoreño Rafael Olmedo hacían el deleite de los salvadoreños.

Su tiempo libre no existía, hasta la fecha de su muerte siempre estuvo activo en cualquier campo del arte, muestra de ello son algunas de sus Operas: "Conrado di Monferrato", "Eloisa”, "Ivannoe”, y "Due Vendette". También "Galanteos en Venecia” y "El Gran Maestro", son muestra de sus zarzuelas. No dejando de lado la música sagrada en la cual incursionó con 10 grandes misas a cuatro voces, coro y gran orquestas; 5 grandes misas réquiem; varias misas pequeñas a dos voces; salves y otras obras de gran relieve místico. Numerosas transcripciones brillantes para piano eran también parte de su repertorio como músico y compositor-arreglista, basándose en algunas óperas italianas y francesas del periodo romántico, y además tríos para piano, violín y violoncello. De su autoría también: 8 sinfonías, varias oberturas, minuetos, poupourries, etc.

\section{ILUSTRACIÓN 3}

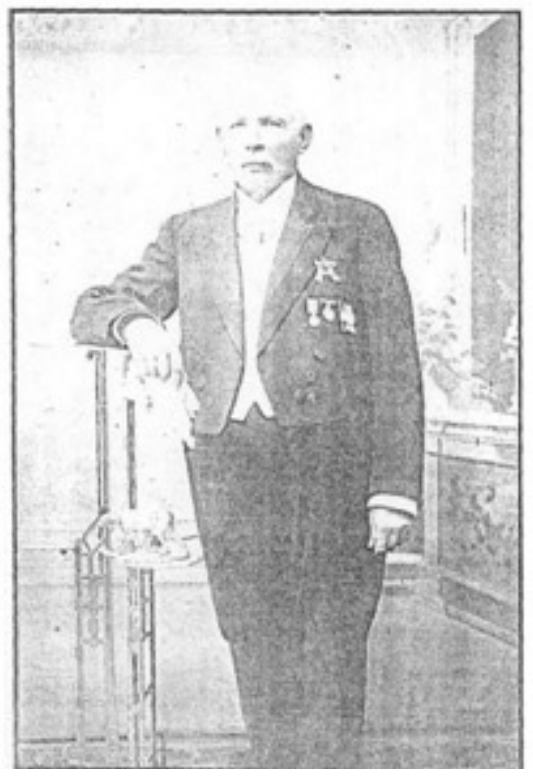

Giovanni Aberle

Fuente:Ward, L. A. Libro Azul de El Salvador. Bureau de publicaciones de América Latina, Imprenta Nacional, 1916, p. 210 
Ningún genio es útil, si no comparte su sabiduría, referente a esto en el campo de la enseñanza escribió un "Tratado de Armonía Contrapunto y Fuga", un "Método de Violín”, otro de piano y "Elementos de Declamación".

Dentro de un aspecto más social, se casó a los 44 años de edad con Gertrudis Pérez Cáceres, oriunda de Ahuachapán; con ella procreó 4 hijos y se radicó en Santa Ana hacia el final de su vida, hecho que sucedió un 28 de febrero de 1930, a los 84 años de edad.

\section{"La función debe terminar".A manera de conclusión}

Indudablemente la historia de la Banda de los Supremos Poderes, como todo otro aspecto de la sociedad, nos puede ilustrar más que solo su propia vida. Es decir que podemos ver varios aspectos sociales y culturales que influyeron en la Banda, pero también podemos ver cómo ésta influyó en los distintos aspectos de la sociedad. Cuando este grupo de músicos se va incorporando a la sociedad civil, empieza a tener este doble flujo de experiencias y beneficios en el cual obtiene insumos como mejores instrumentos, mejores uniformes, obras musicales propias, reconocimiento y posicionamiento social; dando a su vez su arte en beneficio de la población. En cuanto a los distintos extranjeros que integraron a la Banda de los Supremos Poderes, su aporte es fundamental y a lo largo del presente ensayo, se pretende poner a disposición del lector los aspectos más sobresalientes de cada uno de los personajes que de distinta forma se adaptan, integran o aculturizan a El Salvador, los casos más representativos serian el de Heinrich Drews y el de Giovanni Aberle, quienes se quedan en el país por tres o cuatro décadas, interesados por la gente, el prestigio que ganaron, pero que no es otra cosa que el calor de "hogar" que dejaron en su país. Posiblemente, esto suene muy romántico, pero ellos eran "románticos".

Estableciendo su aporte, hay que tomar en cuenta que cada uno de estos músicos venían de países donde la música era algo muy respetado, artístico, y que solo era para aquellos que realmente mostraban talento. Pero en 
El Salvador, los músicos tenían los ánimos, aspiraban a ser reconocidos por ser musiquitos de algún grupo, medio organizado. Estos extranjeros tuvieron que enseñarles hasta cómo agarrar correctamente los instrumentos, cómo producir los sonidos apropiados, tocar en conjunto como un todo. Su labor es pedagógica, pero también artística, de convivencia social, los conciertos, fiestas, retretas y serenatas en la plaza central, son prueba de ello. Hay que medir en qué grado difunden su obra y sus conocimientos, Aberle por ejemplo publica libros sobre aspectos teóricos musicales.

Lo que es claro es que la migración es compleja y se da de muchas formas, por ejemplo podemos ver que algunos músicos llegaban a El Salvador casualmente, los motivos por los cuales salían de su país en algunos casos se debía a contratos ofrecidos, otros salen en giras artísticas y se quedan y otros solo se quedan por temporadas cortas, al cumplir sus contratos se van. Solo en dos casos ya citados, los personajes se quedan en el país que los recibe, durante décadas y son quienes más contribuyeron con la Banda y con la cultura salvadoreña.

En cuanto a la vida de la Banda, esta es fundada en 1841, por tres músicos extranjeros y en 1922, tiene con Aberle, de origen italiano, a su último director. Como aclaración debe decirse que para fines de este trabajo, no se toma en cuenta el periodo del Alemán Paul Müller, ya que bajo este director la Banda se reorganiza y toma el nombre de "Orquesta Sinfónica de los Supremos Poderes", iniciando así una nueva etapa de formación profesional, y esta misma Orquesta, junto con otras organizaciones formará la Orquesta Sinfónica de El Salvador, la cual llega hasta nuestros días, siguiendo una labor de más de 150 años, que muchas veces no es apreciada, ni por la gente ni por el gobierno. 


\section{ILUSTRACIÓN 4}

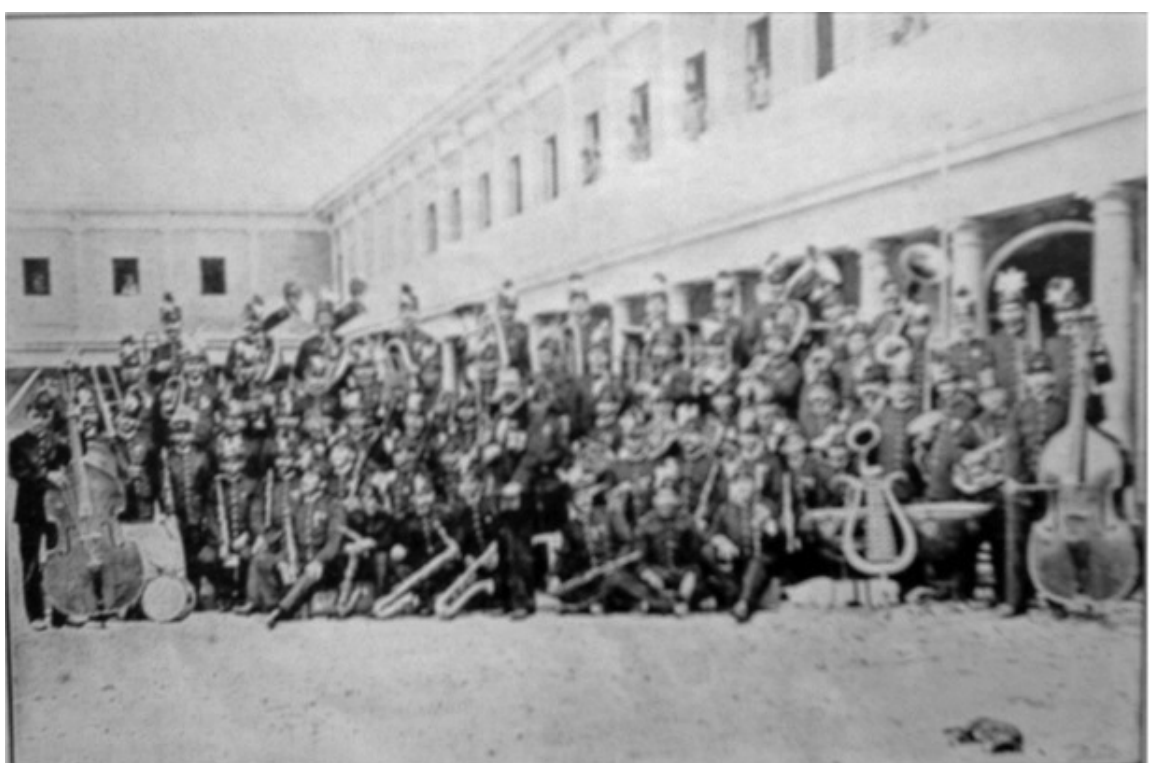

Banda de los Supremos Poderes

Fuente: S.A. "Kaleidoscopio salvadoreño. Personal de la banda de los Altos Poderes de El Salvador”. En: La Quincena, Tomo I, Num. 11, 1 de septiembre de 1903, p. 388

\begin{tabular}{|c|c|c|c|c|}
\hline $\mathrm{N}^{\mathrm{o}}$ & Nombre & Nacionalidad & Llegada al país & Institución \\
\hline 1 & $\begin{array}{c}\text { José Maria Martí- } \\
\text { nez de la Rosa }\end{array}$ & Español & 1841 & Banda Militar \\
\hline 2 & Francisco Libons & Guatemalteco & 1842 & Banda Militar \\
\hline 3 & Joaquín Navarrete & & & \\
\hline 4 & Juan Guido & Italiano & & \\
\hline 5 & Rafael Orozco & Salvadoreño & 1859 & Banda Marcial \\
\hline 6 & Alfredo Lowental & Desconocida & 1860 aprox. & Banda Marcial \\
\hline 7 & Alexis Cousin & Belga & 1860 & $\begin{array}{c}\text { Banda de los } \\
\text { Supremos Poderes } \\
\text { (B.S.P.) }\end{array}$ \\
\hline 8 & Emilio Dresner & Alemán & 1870 & B.S.P. \\
\hline 9 & Heinrich Drews & Alemán & 1876 & B.S.P. \\
\hline 10 & Carlos Malhmann & Alemán & 1906 aprox. & B.S.P. \\
\hline 11 & $\begin{array}{c}\text { Giovanni Enrico } \\
\text { Aberle Sforza }\end{array}$ & Italiano & 1876 & B.S.P. \\
\hline
\end{tabular}

Fuente: Elaboración propia con base en el presente trabajo 


\section{REFERENCIAS BIBLIOGRÁFICAS}

\section{Libros}

Alas, Ciriaco de Jesús. Cartilla musical. San Salvador, Tipografia Musical, 1916

García, Miguel Ángel. Diccionario Histórico, ABA-ANTI. San Salvador, Topografia "La Luz", 1927 (Tomo I)

González Sol, Rafael, Dr. Historia del arte de la música en El Salvador. San Salvador, Imprenta Mercurio, 1940

Ortega Prieto, Jesús. Cultura Musical, desarrollo del programa vigente, 1er curso. San Salvador, Germinal, 1968 Cultura Musical, desarrollo del programa vigente, 2do curso.

San Salvador, Germinal, 1968

Silbermann, Alphons. Estructura Social de la Música. Madrid, Taurus, 1962

Vargas Cullell, María Clara. De las Fanfarrias a las Salas de Concierto, Música en Costa Rica (1840-1940). San José, Costa Rica, Editorial de la Universidad de Costa Rica, Asociación Pro-historia Centro Americana, 2004

Vásquez A., Rafael. Historia de la Música en Guatemala. Guatemala, Tipografia Nacional, 1950

Vides Morán, Raúl. Estética e Historia general del Arte. San Salvador, Dirección de Publicaciones, 1979

Ward, L. A. Libro Azul de El Salvador. San Salvador, Bureau de publicaciones de América Latina, Imprenta Nacional, 1916

\section{Revistas}

S.A. "Kaleidoscopio salvadoreño. Personal de la banda de los Altos Poderes de El Salvador”. En: La Quincena, Tomo I, Num. 11, 1 de septiembre de 1903 Lauria Santiago, Aldo. "Trabajaban para vivir: Descripción de El Salvador por John Newbigging en la década de 1880" Revista Mesoamérica, No. 42, Junio de 2002 


\section{Artículos de Periódicos}

"El parque esta noche". En: Diario del Salvador, sábado 27 de julio de 1895 p. 3 "El parque esta noche". En: Diario del Salvador, lunes 5 de agosto de 1895 p. 3 “Hechos diversos. Los viernes en el Club Unión”. En: Diario del Salvador, 26 de julio de 1895 p. 3

"Velada en el instituto". En: Diario del Salvador, 13 de septiembre de 1895 p. 3 "Velada Lírico - Literaria". En: Diario del Salvador, 14 de Septiembre de 1895 p. 3

Ulloa Cruz, y T'kint, Augusto. Tratado de Amistad, de Comercio y de Navegación entre la Republica del Salvador y la Bélgica, celebrado en Cojutepeque el 15 de febrero de 1859. En: Diario Oficial, Tomo 9, Num. 7, 11 de agosto de 1860, p. 1-4.

\section{Fuentes en soporte electrónico}

Aberle, Giovanni. Let us dance En: http://memory.loc.gov/cgi-bin/ a mpage ? collid $=$ mussm \& file Name $=\mathrm{sm} / \mathrm{sm} 1871 / 00500 / 00545 /$ mussm00545/m visitada el 04-10-2004 (pagina de "la Biblioteca del Congreso)

Cañas Dinarte, Carlos. Plaza Barrios: Un Predio Histórico. En: http://www.elsalvador.com/noticias /EDICIONES ANTERIORES/julio23/NACIONAL/ nacio8.html visitado el 04-10- 2004. (“pagina de El diario de Hoy”) 